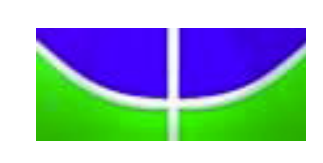

UNIVERSIDADE DE BRASÍLIA

Centro de Excelência em Turismo

Pós-Graduação Lato Sensu

Curso de Especialização em Tecnologia dos Alimentos

\title{
VERIFICAÇÃO E CARACTERIZAÇÃO DA DISTRIBUIÇÃO E COMERCIALIZAÇÃO DO PESCADO NO DISTRITO FEDERAL
}

Fabiana Marinelli Pontes da Rocha

Orientadora: Prof ${ }^{a}$ Dr $^{a}$ Ângela Patrícia Santana 


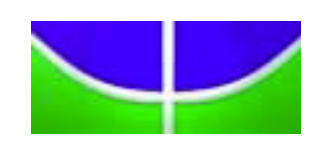

UNIVERSIDADE DE BRASÍLIA

Centro de Excelência em Turismo

Pós-Graduação Lato Sensu

Curso de Especialização em Tecnologia dos Alimentos

\section{VERIFICAÇÃO E CARACTERIZAÇÃO DA DISTRIBUIÇÃO E COMERCIALIZAÇÃO DO PESCADO NO DISTRITO FEDERAL}

Fabiana Marinelli Pontes da Rocha

\section{Orientadora: Prof ${ }^{\mathrm{a}}$ Dr$^{\mathrm{a}}$ Ângela Patrícia Santana}

Monografia apresentada ao Centro de Excelência em Turismo - CET, da Universidade de Brasília - UnB como requisito parcial á obtenção do grau de Especialista em Tecnologia dos Alimentos. 
Rocha, Fabiana Marinelli Pontes da

Verificação e caracterização da distribuição e comercialização de pescado no Distrito Federal - Brasília, 2007.

Monografia (especialização) - Universidade de Brasília, Centro de Excelência em Turismo, 2005.

Orientadora: Prof ${ }^{\mathrm{a}}$. Dr ${ }^{\mathrm{a}}$ Ângela Patrícia Santana.

1. Pescado. 2. Distribuição. 3. Comercialização. I. Título. II. Título: uma revisão. 
UNIVERSIDADE DE BRASÍLIA

Centro de Excelência em Turismo

Pós-Graduação Lato Sensu

Curso de Especialização em Tecnologia dos Alimentos

\section{Fabiana Marinelli Pontes da Rocha}

\section{Aprovado em:}

Orientadora: Prof ${ }^{\mathrm{a}}$. Dr ${ }^{\mathrm{a}}$ Ângela Patrícia Santana

Prof. Ms. Luiz Antônio Borgo

Prof $^{\mathrm{a}}$. Dr ${ }^{\mathrm{a}}$ Wilma Maria Coelho Araújo

Brasília, 22 de maio de 2007. 
Dedico este trabalho ao meu marido, e eterno namorado, e ao meu filho, que compartilharam comigo momentos de vitórias, dificuldades, alegrias, tristezas, através do carinho, paciência, atenção e amor. Quero dividir com eles, neste momento, a felicidade de mais esta conquista e de outras que ainda virão em nossas vidas. 
Agradeço à Deus o dom da vida, a fé, a força e a perseverança na elaboração deste trabalho. Aos meus queridos pais, que me deram a vida, e que através do amor, dedicação, simplicidade e exemplos concretos de lutas, conquistas e, principalmente, respeito ao próximo, contribuíram para que hoje eu realizasse mais essa conquista. Aos meus irmãos, pelo incentivo e apoio que me deram durante essa caminhada. À amiga Carina, por sua amizade e ajuda imensurável nesta monografia. À Prof ${ }^{a} \operatorname{Dr}^{\mathrm{a}}$ Ângela Patrícia pela orientação na confecção desta monografia. E ao chefe do SIPAG, Dr. Fernando Fernandes Fagundes, pelo fornecimento de dados, tornando possível a realização deste trabalho. 


\section{RESUMO}

O pescado é um alimento de alta qualidade nutricional, tendo uma composição rica em minerais e vitaminas hidrossolúveis. Por outro lado, a sua carne é considerada altamente perecível e de fácil deterioração em função da influência de fatores como condições de higiene, transporte e armazenamento, $\mathrm{pH}$ próximo da neutralidade, elevada atividade de água nos tecidos e alto teor de nutrientes, entre outros. O presente trabalho teve por objetivo verificar e caracterizar a procedência, comercialização e distribuição da atividade pesqueira no Distrito Federal e a revisão da importância do pescado no contexto internacional e brasileiro.

PALAVRAS-CHAVE: pescado, composição, perecível, comercialização e distribuição. 


\begin{abstract}
The fished is a food of high nutricional quality, having a rich composition in water soluble minerals and vitamins. On the other hand, its meat is considered highly perishable and of easy deterioration in function of the influence of factors as hygiene conditions, has carried and storage, $\mathrm{pH}$ next to the neutrality, raised activity of water in tissue and high text of nutrients, among others. The present work had for objective to verify and to characterize the origin, commercialization and distribution of the fishing activity in the Distrito Federal; and revision of the importance of the fished in the international and Brazilian context.
\end{abstract}

KEYWORDS: fished, composition, perishable, commercialization and distribution. 


\section{SUMÁRIO}

1. INTRODUÇ̃̃

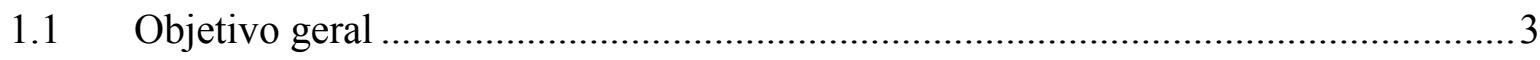

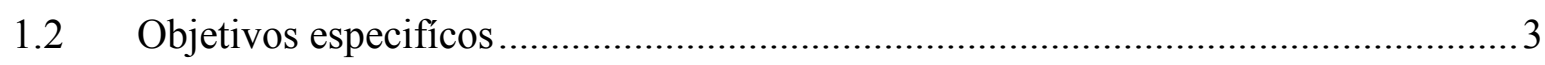

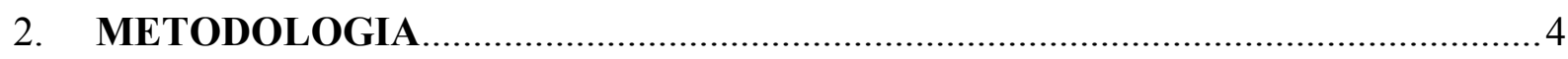

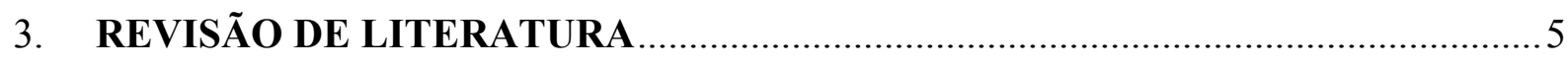

3.1 Cenário Global da atividade pesqueira ........................................................... 5

Cenário Brasileiro ....................................................................................

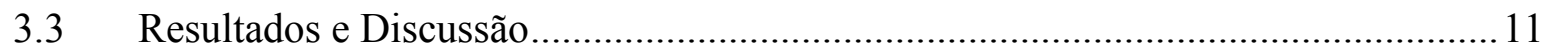

3.3.1 O Distrito Federal no contexto do mercado pesqueiro ................................ 11

3.4 Qualidade do pescado e os perigos da indevida manipulação e conservação .......... 15

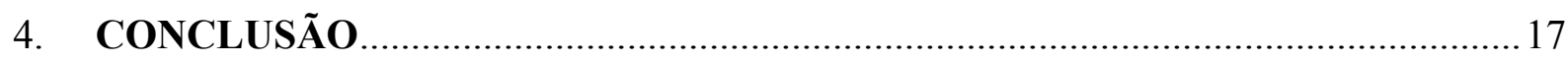

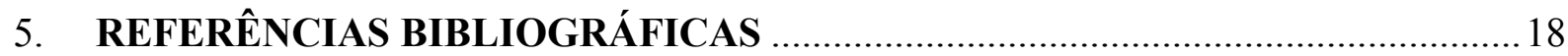




\section{INTRODUÇÃO}

O pescado é considerado um alimento de fundamental importância para a humanidade em virtude de seu sabor largamente apreciado, de sua capacidade nutritiva como fonte de proteínas, de vitaminas e de compostos inorgânicos essenciais. Suas proteínas apresentam alto valor nutritivo com excelente balanceamento de aminoácidos essenciais, sendo especialmente rico em lisina. O pescado é excelente fonte de minerais fisiologicamente importantes, tais como: $\mathrm{Mg}^{2+}$, $\mathrm{Mn}^{2+}, \mathrm{Zn}^{2+}$ e $\mathrm{Cu}^{2+}$, além de ser rico em vitaminas hidrossolúveis do complexo $\mathrm{B}$ e vitaminas lipossolúveis A e D (OGAWA; MAIA, 1999).

A atividade pesqueira ocorre em águas marítimas, estuarinas (junção de água doce com água salgada) e em água doce. A exploração dos recursos pesqueiros ocorre por meio da pesca extrativa, que extrai o pescado como um recurso natural renovável, e também por meio da pesca não extrativa, que tem o pescado como um produto cultivado, no caso da aqüicultura (ABDALLAH, 1998).

Segundo a Food Agriculture Organization (FIPERJ, 20001) o maior produtor pesqueiro mundial em 2001, foi a China, cuja produção corresponde a 49,6 milhões de toneladas, seguido do Peru com 10,6 milhões toneladas, Japão com 6,4 milhões de toneladas, Índia com 5,7 milhões de toneladas e EUA com 5,2 milhões de toneladas. O Brasil encontra-se em $27^{\circ}$ lugar. Portanto, a produção aquícola mundial é dominada pelos países Asiáticos e a produção corresponde a $85 \%$ da produção mundial. Nesses países, os sistemas da aqüicultura são semi-intensivos e extensivos (BORGES, 2005).

Desde 1990, a aqüicultura mundial vem apresentando crescimento anual de $8,9 \%$, muito superior ao crescimento da indústria pesqueira oriunda da captura $(1,4 \%)$ e àquele dos sistemas de produção de proteína de animais terrestres $(2,8 \%)$, para o mesmo período. No Brasil, a aqüicultura também vem despontando como atividade promissora, registrando um crescimento superior à média mundial, passando de 20,5 mil toneladas, em 1990, para 210 mil toneladas, em 2001, com uma receita de US\$ 830,3 milhões. No período de 1990 - 2001, o Brasil apresentou um crescimento de aproximadamente $825 \%$, enquanto a aqüicultura mundial cresceu $187 \%$ no mesmo período. $\mathrm{O}$ resultado desse crescimento fica evidenciado na classificação mundial estabelecida pela FAO 2001, em que o Brasil se encontrava na 36 colocação em 1990, passando a ocupar a $19^{a}$ posição em 2001, assim como a $13^{a}$ posição na geração de renda bruta. No ranking da 
América do Sul, o Brasil encontra-se em segundo lugar, com 210 mil toneladas, sendo superado apenas pelo Chile - 631,6 mil toneladas (FILHO, 2006).

De acordo com as últimas informações levantadas pelo Instituto Brasileiro de Meio Ambiente e dos Recursos Naturais Renováveis - IBAMA, a piscicultura, na classificação nacional por produção, respondeu, em 2002, por uma produção de aproximadamente 158.058 toneladas, correspondendo a $67,1 \%$ da produção total da aqüicultura, que foi de 235.640 toneladas (IBAMA, 2004).

De acordo com Oliveira (1996), o sistema de abastecimento alimentar no Brasil baseia-se em uma grande rede de supermercados de tamanho variado e complementado por outras estruturas como açougues, peixarias, aviários, quitandas, mercados, feiras livres e padarias. Segundo Giova (1997), os varejistas são o último ponto da cadeia comercial produtorconsumidor, e o controle de qualidade do produto passa por manuseio, armazenamento e exposição nos locais de comercialização.

O Distrito Federal é importante mercado consumidor de pescados. A demanda atinge 11.231 t/ano e o consumo per capita é $12,80 \mathrm{Kg}$, acima da média nacional, conforme Teixeira e Madrid (1998). O pescado é alimento de alta perecibilidade, e o Distrito Federal dista geograficamente dos principais centros produtores, devido a isso a importância de avaliar continuamente as condições de comercialização desses produtos é fundamental sob os aspectos de desperdício e de saúde pública (ALVES et al., 2002).

No Distrito Federal (DF), comercializa-se pescado em supermercados de tamanhos variados, peixarias e feiras. Os supermercados respondem pela maior comercialização porque são a maior parcela de estabelecimentos por ramo alimentício (TEIXEIRA; MADRID, 1998; apud ALVES et al., 2002).

De acordo com a ICMSF, "para manter a microbiota natural do pescado cru em níveis convenientemente baixos e livres da contaminação por patógenos, é necessário que todo o seu processamento seja efetuado sob condições sanitárias rigorosas. Durante a distribuição e comercialização desse produto é de extrema importância que o pescado seja mantido a temperaturas inferiores a 4,0 $0^{\circ}$ " (apud SOARES, 2005).

De acordo com Franco e Landgraf (2003), a deterioração do pescado deve-se a elevada atividade de água (Aw), a composição química, ao alto teor de gordura insaturada facilmente oxidável e ao $\mathrm{pH}$ próximo da neutralidade que caracterizam alta perecibilidade o que constitui problema para comercialização. 
O presente trabalho teve como objetivo geral fazer um levantamento do segmento da distribuição e comercialização de pescado no Distrito Federal e, como objetivo específico, localizar e identificar os segmentos da cadeia de distribuição e os pontos de comercialização do pescado na região, bem como apontar os principais problemas dessa cadeia, tendo em vista ser um alimento altamente perecível e passível de deterioração bacteriana e existir pouca informação a respeito desse assunto.

\subsection{Objetivo geral}

O presente trabalho teve como objetivo geral fazer um levantamento do segmento da distribuição e comercialização de pescado no Distrito Federal.

\subsection{Objetivos específicos}

- localizar e identificar os segmentos da cadeia de distribuição e os pontos de comercialização do pescado na região, bem como apontar os principais problemas dessa cadeia; - promover uma revisão da economia do pescado no contexto internacional e brasileiro. 


\section{METODOLOGIA}

A pesquisa foi realizada por meio de estudo descritivo (revisão bibliográfica) e estudo de levantamento de dados realizados na cidade de Brasília (DF) no período entre novembro de 2006 a abril de 2007.

Os dados referentes ao Distrito Federal foram fornecidos pelo Serviço de Inspeção de Produtos Agropecuário (SIPAG-MAPA), cujos registros são realizados por meio de tabelas enviadas mensalmente pelos entrepostos oficiais existentes.

Com a finalidade de obter dados da produção pesqueira no país e a legislação pertinente foram pesquisados artigos científicos nos sites de periódicos da CAPES e do SCIELO, em português e inglês; em revistas cientificas (Revistas: Higiene Alimentar e do ITAL), e no site do Ministério da Agricultura (MAPA), IBAMA, FAO e IBGE. As palavras-chave utilizadas foram: pescado, comercialização, distribuição, piscicultura, fish, fished Brazilian production. 


\section{REVISÃO DE LITERATURA}

\subsection{Cenário Global da atividade pesqueira}

Pescado é uma denominação genérica que compreende os peixes, crustáceos, moluscos, anfíbios, quelônios e mamíferos de água doce ou salgada usados na alimentação humana, de acordo com o Decreto no 30691 do Ministério da Agricultura - MA (BRASIL, 1952). Segundo a Portaria $n^{\circ} 185$ (BRASIL, 1997), peixes são animais aquáticos de sangue frio, excluídos os mamíferos aquáticos, animais invertebrados e anfíbios.

O pescado pode ser classificado, de acordo com a sua natureza, em pescado fresco, resfriado e congelado. Fresco não sofre processo de conservação, exceto a ação do gelo. Resfriado é acondicionado em gelo e mantido a temperatura entre $-0,5$ a $-2^{\circ} \mathrm{C}$. Congelado é tratado por processos adequados de congelação, em temperatura não superior a $-25^{\circ} \mathrm{C}$ (BRASIL, 1952).

Segundo a FAO (2000), em 1998, a produção dos sete maiores países pesqueiros atingiu a metade da captura total mundial de 86,3 milhões de toneladas, sendo que a China foi responsável por 17,2 milhões de toneladas, o Japão por 5,3 milhões de toneladas, os Estados Unidos por 4,7 milhões de toneladas, a Rússia por 4,5 milhões de toneladas, o Peru por 4,3 milhões de toneladas, a Indonésia por 3,7 milhões de toneladas e o Chile por 3,3 milhões de toneladas.

$\mathrm{O}$ surgimento da aqüicultura trouxe um novo impulso à oferta mundial de pescado. Em 1998, a produção conjunta da pesca extrativa e da aqüicultura atingiu 117,2 milhões de toneladas incluindo peixes, crustáceos e moluscos, tendo a aqüicultura contribuído com 30,9 milhões de toneladas, ou 26,3\% do total (FISHTEC, s.d).

Cabe acentuar o papel da China, no cenário mundial, uma vez que sozinha contribui com $84 \%$ da produção total da aqüicultura. No âmbito interno, a aqüicultura já representa $60 \%$ do total de pescado produzido pelo país (FISHTEC, s.d.).

Os produtos da aqüicultura estão conquistando um destaque cada vez maior na oferta mundial de pescado, ultrapassando, em alguns casos, os produtos da pesca. Atualmente, para cada 10 ostras, salmões do Atlântico e carpas, nove são provenientes da aqüicultura, assim como o são quatro entre cada cinco mexilhões e um em cada quatro camarões (FISHTEC, s.d.).

Hoje em dia, já se pode afirmar que a aqüicultura produz mais pescado, direcionado para o consumo humano direto, do que a pesca extrativa. Entre 1984 e 1998 a aqüicultura aumentou em quase $80 \%$ a sua participação no consumo per capita de pescado no mundo, saltando de 1,2 para 
2,1 Kg/hab/ano, com exceção apenas da China, que sozinha contribuiu com $84 \%$ da produção total da aqüicultura mundial (FAO, 2000).

Em 1997, dos 93,9 milhões de toneladas de pescado disponíveis para consumo humano, apenas 5,2 milhões foram consumidos no continente africano (7,1 Kg/hab./ano), enquanto 31,7 milhões foram consumidos na Ásia, com exceção da China. Apenas na China, estima-se o consumo de outras 30 milhões de toneladas (FAO, 2000).

Em 1998, o mercado internacional de pescado e derivados exportados foi estimado em US\$ 51,3 bilhões, apresentando uma queda de 3,8\% em relação ao ano anterior. Quanto às importações, essas totalizaram US\$ 55 bilhões, 2,8\% menos do que 1997 (FAO, 2000).

Os mercados de maior peso no comércio internacional de pescado continuam sendo o europeu, o americano e o japonês, para este último, estima-se uma demanda reprimida de oito milhões de toneladas de pescados atuais. Infelizmente, a crise asiática refletiu numa redução das importações no período de 1996 a 1999, mas, agora, o continente começa dar sinais de recuperação (FISHTEC, s.d.).

Em 1998, os EUA e o Canadá importaram, juntos, cerca de US\$ 6 bilhões em pescados, especialmente camarões (Penaeus spp.), salmões (Salmo salar) e tilápias (T. rendalli) (FAO, 2000). No mesmo ano, os europeus foram responsáveis por importações da ordem de US\$ 4 bilhões. Os países africanos, latino-americanos e a China importaram cerca de US\$ 1 bilhão cada, enquanto a Oceania fez importações da ordem de US\$ 0,5 bilhões (FAO, 2000).

Cada vez mais os produtos cultivados estão influenciando os negócios externos dos países. Na Noruega a aqüicultura já é a terceira maior indústria exportadora depois do petróleo e do gás; a Tailândia, em 1997, exportou mais de US\$ 1,5 bilhões em produtos aqüícolas. No continente americano, destacam-se países que ingressaram na aqüicultura industrial há menos de 10 anos, como o Equador e o Chile, tornando-se potências mundiais em algumas cadeias. No Equador, a carcinicultura marinha tornou-se a segunda maior indústria exportadora depois do petróleo e gerou, em 1998, receita de US\$ 850 milhões com 1 milhão de empregos diretos e indiretos. O Chile é o segundo produtor mundial de salmões e sua aqüicultura representou quase 40\% (US\$ 720 milhões) da receita de exportação de pescado, representando uma geração de mais de 25 mil empregos diretos (FISHTEC, s.d.).

Em níveis globais, o consumo per capita de pescado expandiu-se cerca de $230 \%$ a partir da década de 50, atingindo 16,2 Kg/hab/ano, em 2002 (FAO, 2004). Em países como o Japão, este 
consumo é de $72 \mathrm{Kg} / \mathrm{hab} / \mathrm{ano}$, enquanto no Brasil, é de 4,59 Kg/hab/ano, valor inferior às médias sul-americanas ( $8 \mathrm{Kg} / \mathrm{hab} / \mathrm{ano}$ ) e africanas (7,1 Kg/hab/ano) (IBGE, 2005).

\subsection{Cenário Brasileiro}

No Brasil, faz-se captura de pescados por quatro modalidades: extrativista marítima, extrativista de água-doce; cultivo marinho e cultivo de água-doce (BRASIL, 2002). A produção atual estimada é de 600 mil toneladas e, ao contrário dos países mais desenvolvidos, deve continuar crescendo, embora as taxas estejam cada vez menores. Em 1985, a produção de pescado nacional atingiu cerca de 1 milhão de toneladas, entrando em declínio desde então. Além da super exploração dos estoques, a captura vem sendo prejudicada pelo atraso tecnológico da frota, falta de políticas específicas e pela desatualização da legislação da pesca no Brasil (FISHTEC, s.d.).

O Brasil produziu, em 2004, 1.015.914,0 toneladas de pescado. Em 2003, observou-se um acréscimo na produção total, na ordem de 2,6\%, determinado principalmente, pelos desempenhos da pesca extrativa marinha e continental que apresentaram um crescimento de 3,2\% e 8,2\%, respectivamente. A aqüicultura continental também apresentou um crescimento de $2 \%$ em 2004, entretanto a maricultura em 2004, apresentou um decréscimo de 11,9\%, quando comparado ao ano de 2003 (Quadro 1) (IBAMA, 2004).

Quadro 1: Produção de pescado em 2004 no Brasil.

\begin{tabular}{|l|c|c|}
\hline \multicolumn{1}{|c|}{ Produção (t) } & $\mathbf{2 0 0 3}$ & $\mathbf{2 0 0 4}$ \\
\hline Pesca extrativa marinha & $484.592,5$ & $500.116,0$ \\
\hline Pesca extrativa continental & $227.551,0$ & $246.100,5$ \\
\hline Maricultura & $101.003,0$ & $88.967,0$ \\
\hline Aqüicultura continental & $177.125,5$ & $180.730,5$ \\
\hline Total & $\mathbf{9 9 0 . 2 7 2 , 0}$ & $\mathbf{1 . 0 1 5 . 9 1 4 , 0}$ \\
\hline
\end{tabular}

Fonte: IBAMA, 2004.

Os principais produtores de pescados são a região Sul e a Nordeste do Brasil. Em 2004, a região Nordeste atingiu 323.269,5 toneladas e a região Sul 234.564,0 toneladas (IBAMA, 2004).

Contudo vale ressaltar que a região Sul é a maior produtora de pescado do Brasil, através da pesca extrativa marinha, onde se destaca o estado de Santa Catarina, segundo maior produtor de pescado do Brasil, com 148.915,0 toneladas, em 2004. O estado do Rio Grande do Sul 
registrou uma produção de 66.113,5 toneladas. A produção de 19.535,5 toneladas, em 2004, do estado do Paraná, registrou um decréscimo de 21,2\% em relação ao ano de 2003. Esse fato devese a problemas no sistema de geração da estatística pesqueira (IBAMA, 2004).

A região Norte produziu 252.361,0 toneladas de pescado, no ano de 2004, onde os estados Pará e Amazonas são os maiores produtores de pescado da região. O estado do Pará, maior produtor de pescado do país, com produção de 153.806,0 toneladas e o Amazonas, com 64.470,5 toneladas de pescado, em 2004. As espécies de peixes que mais contribuíram para esta produção foram: curimatã (Prochilodus scrofa) 167,4\%, tambaqui (Colossoma macropomum) 75,8\%, piramutaba (Brachynlaiystama vaillanti) 18,3\% e a dourada (Salminus maxillosus) 13,7\% (IBAMA, 2004).

A região Sudeste, em 2004, registrou uma produção de 161.437,5 toneladas. O estado do Rio de Janeiro produziu 71.215,0 toneladas, registrando acréscimo de 31,2\% na produção de pescado, devido ao aumento na produção da sardinha-verdadeira (Sardinella brasiliensis). No estado do Espírito Santo observou-se um decréscimo de 1,3\% em relação a 2003, devido à queda na produção do peroá (Balistes capricus) que passou de 2.594,5 toneladas em 2003 para 1.341,0 toneladas em 2004. O estado de São Paulo apresentou um crescimento de 1,6\% comparado a 2003, decorrente do crescimento da produção da sardinha-verdadeira (Sardinella brasiliensis) de 94,7\%; da tainha (Mugil cephalus) com 69,9\%; bonito (Euthynnus alletteratus) com 51,4\% e a produção de polvo que apresentou um incremento de 140,5\%, devido a uma pesca direcionada para este recurso pesqueiro (IBAMA, 2004).

A região Centro-Oeste produziu 44.282,0 toneladas de pescado, apresentando crescimento de $1,4 \%$ na produção no ano de 2004.

A maricultura com uma produção de $88.967,0$ toneladas representa $8,8 \%$ da produção de pescado total do Brasil e apresentou um crescimento negativo de 11,9\% em 2004. Os camarões marinhos têm sua maior produção concentrada na região Nordeste, embora ocorra nas regiões Sudeste e Sul. Os estados do Rio Grande do Norte, Ceará, Bahia e Pernambuco são os maiores produtores de camarão cultivado do Brasil (IBAMA, 2004).

A balança comercial, em 2004, registrou um saldo positivo de US\$ 183,9 milhões, $18,12 \%$ menor que o verificado em 2003, resultado da diferença entre as exportações, no montante de US\$ 436,3 milhões e as importações, no valor de US\$ 252,4 milhões. Este decréscimo se deu não só em virtude da diminuição no volume das exportações $(6 \%)$, mas também pelo crescimento no volume das importações $(4,03 \%)$. Em termos de valor, o 
crescimento das exportações, no ano de 2004, foi de apenas 2,07\%, enquanto as importações tiveram um crescimento significativo de $24,40 \%$, em relação a 2003.

Outro fator que merece destaque diz respeito aos preços médios das exportações. Já em 2001, mostravam-se declinantes (US\$ 4,180/t, em 2000 e US\$ 3,930/t, em 2001). Em 2002, constatou-se uma redução de 8,8\% (US\$ 3,583/t), em relação a 2001. Em 2003, observou-se uma ligeira recuperação (US\$ 3,759/t) e, para o ano em análise, verificou-se um crescimento de 8,5\% (US\$ 4,077/t), próximo dos preços praticados no início da década. Este fato contribuiu para que o superávit na balança comercial brasileira de produtos pesqueiros, em 2004, não se mostrasse menos expressivo, vez que tivemos uma redução nas exportações de 6.705 toneladas de pescado (IBAMA, 2004).

O Brasil, em 2004, exportou para 73 países. Os Estados Unidos permaneceram na primeira posição, embora sua participação relativa tenha reduzido em 7,74\%. Suas compras concentraramse, principalmente, em lagosta (US\$ 78,2 milhões), camarão (US\$ 42,2 milhões) e outros peixes frescos/refrigerados (US\$ 19,4 milhões), os quais (esses três produtos) representaram 81,2\% das nossas exportações dirigidas àquele mercado. Vale destacar que as nossas vendas de camarão aos Estados Unidos, em 2003, foram mais que o dobro (US\$ 92,1 milhões) do que as efetivadas em 2004; a Espanha teve sua participação aumentada em 2,31\% e permaneceu como o segundo comprador dos nossos produtos, destacando-se o camarão (US\$ 67,1 milhões); a França, passou a ostentar o primeiro maior importador de camarão do Brasil (US\$ 71,3 milhões), teve sua participação aumentada em 4,06\%; a Holanda absorveu 4\% das exportações totais brasileiras, principalmente camarão $(85,13 \%)$, no valor de US\$ 14,9 milhões, colocando-se como o quarto principal mercado importador do Brasil. O Japão, que importa preferencialmente camarão (US\$ 11,8 milhões) do nosso país, aumentou sua participação de 2,98\% em 2003 para 3,82\% em 2004; Portugal apareceu como o sexto principal país comprador do nosso pescado, tendo despendido US \$ 5,3 milhões na importação de peixes frescos/refrigerados e US\$2,8 milhões em camarão, e a Argentina, que destinou aproximadamente 60,56\% das suas compras em 2004 em preparações e conservas de atum e $12,72 \%$ na aquisição de bonitos-listrados congelados do país, viu sua participação, em termos de valor, aumentar de 1,37\% para 1,79\% (IBAMA, 2004).

Os principais fornecedores de pescados ao Brasil, em 2004, foram: Noruega, Argentina, Chile, Venezuela, Portugal, Uruguai, Peru, Equador e Rússia (Quadros 2 e 3 ) (IBAMA, 2004). 
Quadro 2: Principais fornecedores de pescados ao Brasil, 2003 - 2004.

\begin{tabular}{|l|c|c|c|c|c|c|c|c|}
\hline \multicolumn{1}{|c|}{ Ano } & \multicolumn{5}{c|}{$\mathbf{2 0 0 3}$} & \multicolumn{4}{c|}{$\mathbf{2 0 0 4}$} \\
\hline \multicolumn{1}{|c|}{ Países } & $\mathbf{t}$ & $\mathbf{\%}$ & $\mathbf{U S \$}$ & $\mathbf{\%}$ & $\mathbf{t}$ & $\mathbf{\%}$ & $\mathbf{U S \$}$ & $\mathbf{\%}$ \\
\hline Noruega & 16.952 & 11,12 & 65.117 & 32,09 & 23.520 & 14,82 & 94.413 & 37,40 \\
\hline Argentina & 37.235 & 24,41 & 43.307 & 21,34 & 36.696 & 23,13 & 51.811 & 20,52 \\
\hline Chile & 13.871 & 9,09 & 34.758 & 17,13 & 19.341 & 12,19 & 48.208 & 19,10 \\
\hline Venezuela & 32.265 & 21,16 & 11.924 & 5,88 & 37.726 & 23,78 & 14.414 & 5,71 \\
\hline Portugal & 2.133 & 1,40 & 9.899 & 4,88 & 2.230 & 1,41 & 11.964 & 4,74 \\
\hline Uruguai & 14.001 & 9,18 & 9.552 & 4,71 & 13.327 & 8,40 & 8.069 & 3,20 \\
\hline Peru & 3.399 & 2,16 & 4.671 & 2,22 & 3.711 & 2,34 & 4.029 & 1,60 \\
\hline Equador & 1.447 & 0,92 & 2.454 & 1,17 & 2.046 & 1,29 & 3.370 & 1,33 \\
\hline Rússia & 9.784 & 6,42 & 5.237 & 2,58 & 2.737 & 1,73 & 1.149 & 0,46 \\
\hline $\begin{array}{l}\text { Outros } \\
\text { Países }\end{array}$ & 26.273 & 17,23 & 23.137 & 11,40 & 17.327 & 10,92 & 15.027 & 5,95 \\
\hline Total & 157.360 & 100 & 210.056 & 100 & 158.661 & 100 & 252.454 & 100 \\
\hline
\end{tabular}

Fonte: SECEX - IBAMA

Quadro 3: Principais pescados importados pelo Brasil, em 2004.

\begin{tabular}{|l|c|}
\hline \multicolumn{1}{|c|}{ Países } & Pescados \\
\hline Noruega & bacalhau \\
\hline Argentina & Filés de merluza congelados e filés de outros peixes congelados \\
\hline Chile & Salmão e filés de peixes congelados \\
\hline Venezuela & sardinha \\
\hline Portugal & bacalhau \\
\hline Uruguai & pescadas \\
\hline Peru & Produtos pesqueiros \\
\hline Equador & Produtos pesqueiros \\
\hline Rússia & sardinha \\
\hline
\end{tabular}

Fonte: IBAMA, 2004.

O consumo de pescados, em termos quantitativos e qualitativos, também é bastante diferente dentro do território nacional. Segundo os dados da Pesquisa de Orçamento Familiar (POF), 2002 - 03, levantados e tabulados pelo Instituto Brasileiro de Geografia e Estatística 
(IBGE), a Região Norte é a que apresenta maior consumo per capita, sendo dez vezes maior do que a da Região Sudeste (Quadro 4). Este elevado consumo per capita está sendo influenciado pela elevada produção de pescados destas Regiões. Este exemplo ilustra claramente como a demanda por alimentos frescos estaria ligada à produção local (SONODA, 2006).

Quadro 4: Aquisição domiciliar per capita anual de pescados, em kg/hab/ano, POF* 2002-03.

\begin{tabular}{|l|c|c|c|c|c|c|}
\hline \multicolumn{1}{|c|}{ Produtos } & Brasil & Norte & Nordeste & Sudeste & Sul & $\begin{array}{c}\text { Centro- } \\
\text { Oeste }\end{array}$ \\
\hline Pescados & 4,59 & 24,67 & 4,97 & 2,17 & 1,78 & 1,36 \\
\hline Pescados de água salgada & 1,82 & 5,52 & 2,23 & 1,46 & 0,82 & 0,40 \\
\hline Pescados de água doce & 2,12 & 17,76 & 1,78 & 0,34 & 0,46 & 0,53 \\
\hline Pescados não especificados & 0,65 & 1,39 & 0,96 & 0,37 & 0,50 & 0,43 \\
\hline
\end{tabular}

* considerou apenas o consumo domiciliar.

Fonte: IBGE, 2005.

\subsection{Resultados e Discussão}

\subsubsection{O Distrito Federal no contexto do mercado pesqueiro}

Em 2004, o Distrito Federal produziu 820,0 toneladas de pescado de água doce (IBAMA, 2004).

No levantamento junto ao serviço de inspeção de produtos agropecuários (SIPAG MAPA) referente a 2006, foi obtida a informação de que a maioria do pescado tem procedência do estado do Pará e Santa Catarina $( \pm 70 \%)$. Aparecem pescados de outras localidades como: Amazonas, Pernambuco, São Paulo, Paraíba e Espírito Santos.

Atualmente, no Distrito Federal existem cinco entrepostos de pescados oficiais, sendo que um em 2006 não estava em atividade. Entre os quatro entrepostos em atividade em 2006, foi identificada a entrada de um volume mensal aproximadamente de pescado no mercado do Distrito Federal da ordem de 197,9 toneladas distribuídas em aproximadamente 9 variedades distintas, cujas quantidades e características estão expostas nos Gráficos 1, 2, 3 e 4. Salienta-se que neste volume não foram inclusos os pescados do mercado clandestino. 
Gráfico 1: Em relação ao ingresso mensal do pescado no mercado do Distrito

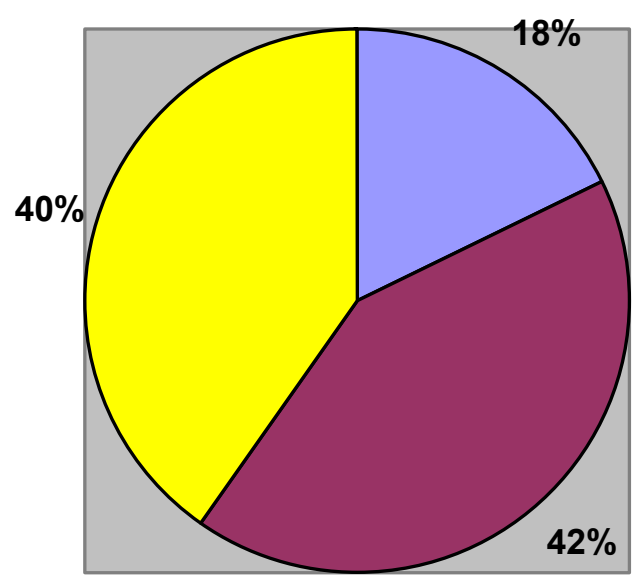

$\square$ Água salgada
$\square$ Água doce
$\square$ Não identificados

Federal

Gráfico 2: Composição do pescado de água doce no mercado do Distrito Federal

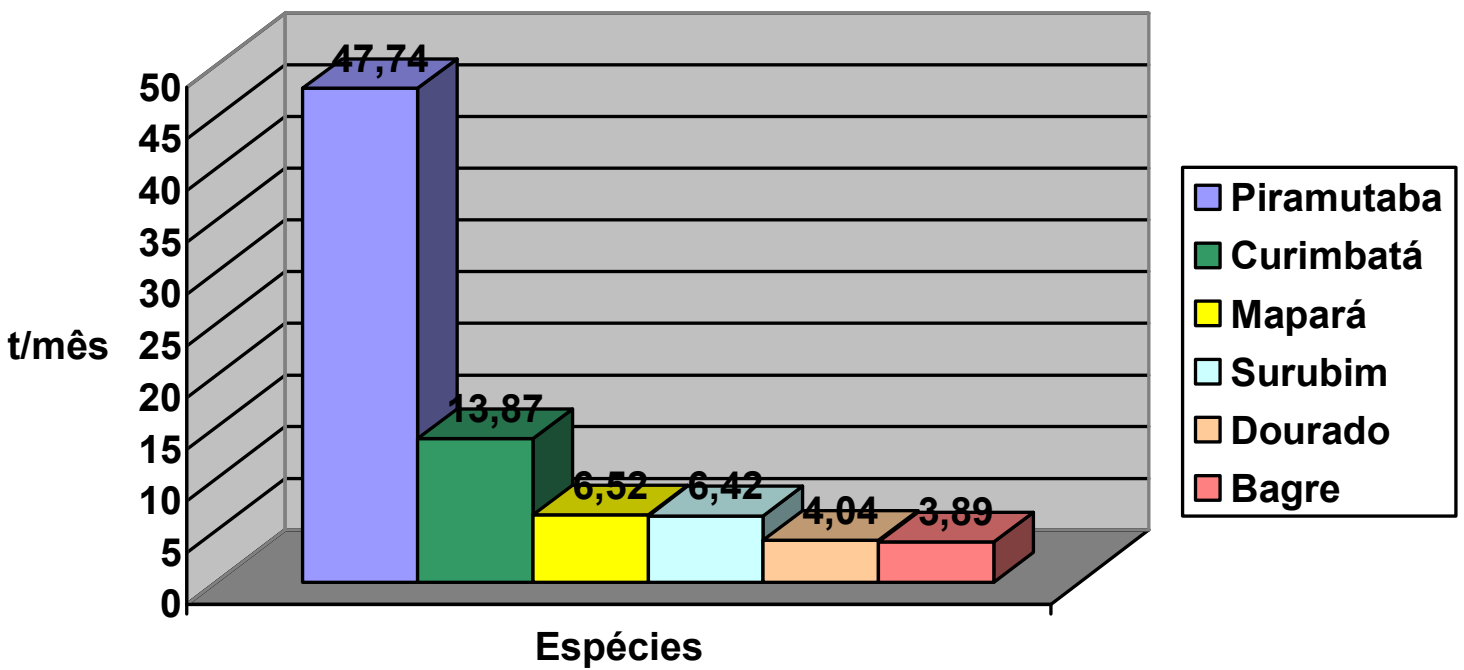

Quanto à quantidade de pescado que ingressa no mercado do Distrito Federal, do total de pescado informado, verificou-se que cerca de 6 são de espécies oriundas de água doce, dos quais a Piramutaba é a mais representativa. As espécies de peixe Dourado e Piramutaba são oriundas do estado do Pará. As espécies peixe Bagre, Mapará, Piramutaba e Surubim têm procedência do estado do Amazonas. 
Gráfico 3: Composição do pescado de água salgada no mercado do Distrito Federal

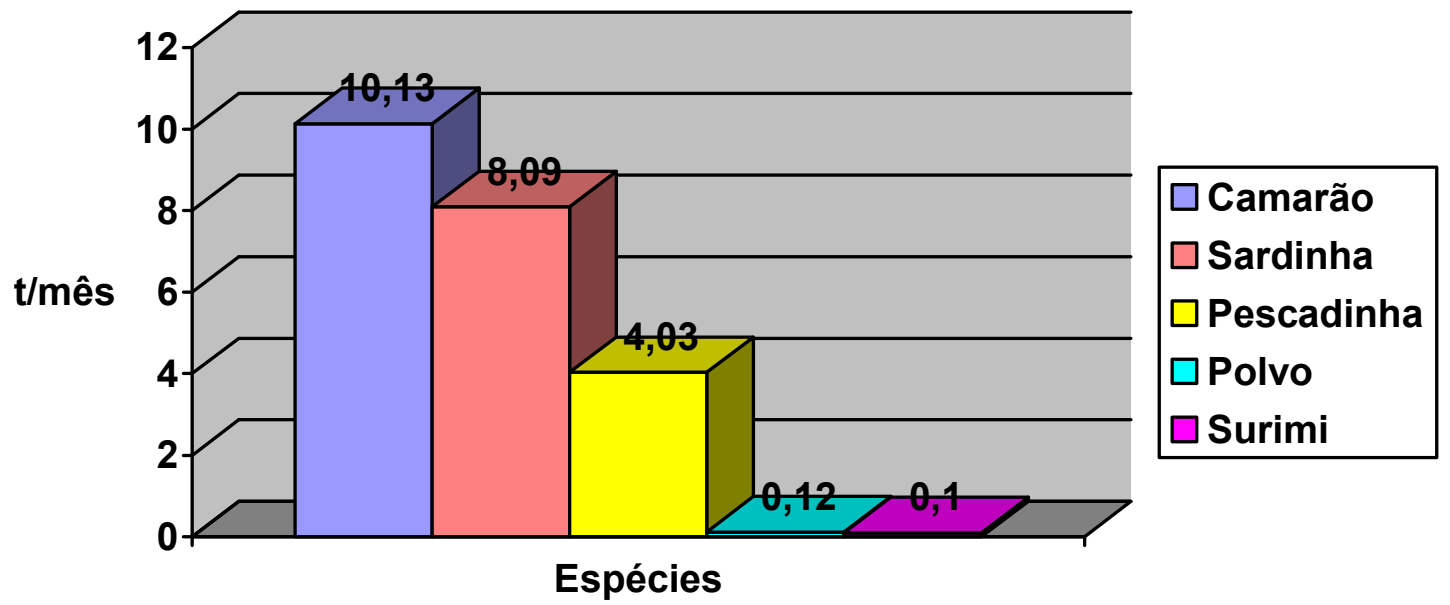

No grupo dos peixes de água salgada, o mercado informou a entrada de aproximadamente 35,6 toneladas/mês.

O volume de camarão que entrou no Distrito Federal em 2006 tem procedência do estado de Santa Catarina e Pernambuco, sendo 9,13 toneladas oriundo de Santa Catarina. O total de sardinha, polvo e surimi tem origem no estado de Santa Catarina. A pescadinha tem procedência dos estados de Santa Catarina e Paraíba

Gráfico 4: Composição do pescado não identificado no mercado do Distrito Federal

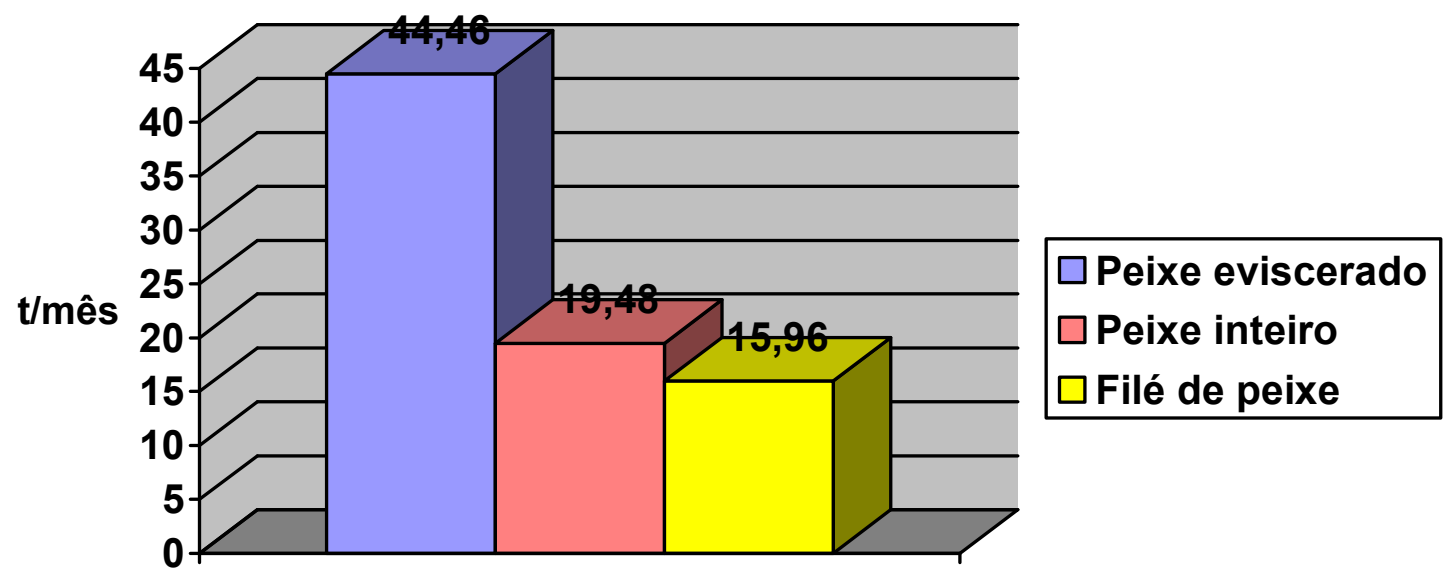

\footnotetext{
Espécies não identificadas
} 
As espécies de peixe não identificadas possuem origens variadas, sendo o peixe eviscerado oriundo de quatro estados Santa Catarina, Pará, Amazonas e do próprio Distrito Federal; o peixe inteiro tem origem somente de dois estados: Amazonas e Santa Catarina; já o filé de peixe tem origem de vários estados como Santa Catarina, Paraíba, Pernambuco, Amazonas, Pará, São Paulo e Espírito Santos.

$\mathrm{Na}$ freqüência de compras de pescado foi identificada regularidade de compra mensal, mas não há regularidade de espécies nem de quantidades. Em relação às formas de apresentação do pescado, verificou-se que grande parte é vendido sem cabeça (60\%) e congelado (100\%). E em relação a circulação do pescado no mercado local existe uma pequena diferença entre o volume de entrada de pescado na cidade e o que é efetivamente comercializado internamente, pois parte do pescado é exportado para outros estados como: Tocantins, Goiás, Bahia, Minas Gerais e São Paulo. Os estabelecimentos não quiseram informar os níveis de preços do pescado processado, os valores mínimo e máximo, alegando problemas em relação à concorrência. Os pontos principais de distribuição desses entrepostos são supermercados, mercados, restaurantes e hotéis, não havendo freqüência de compra por parte desses pontos de comercialização, variando conforme a demanda. 


\subsection{Qualidade do pescado e os perigos da indevida manipulação e conservação}

Entre os produtos de origem animal, o pescado é um dos mais susceptíveis ao processo de deterioração. Alguns dos fatores que contribuem para esse fato incluem as condições de higiene, transporte e armazenamento, o pH próximo à neutralidade, a elevada atividade de água nos tecidos, o alto teor de nutrientes, a quantidade de lipídios insaturados, a presença de pouco tecido conjuntivo e a ação das enzimas autolíticas presente (FRASSER; SUMAR, 1998; SOARES et al., 1998; MAUSSE, 2000; ANDRADE, 2006).

Conservar esses produtos requer rigoroso controle de qualidade, da captura à comercialização. A manutenção da cadeia de frio constitui ponto importante na obtenção de um produto de qualidade. Produtos devem ser comercializados em locais limpos, sob temperatura adequada; dessa forma, os balcões expositores requerem condições ideais de temperatura (PARANÁ, 1993; apud ALVES et al., 2002).

A ação dos microorganismos se inicia no momento da captura e se estende por todas as etapas de processamento. Diversos fatores interferem na natureza e na velocidade do processo de deterioração do pescado. Leitão também relaciona parâmetros como: tipo de pescado, grau de exaustão do pescado na captura, natureza e extensão da contaminação microbiana e temperatura de armazenamento, à parte condições higiênico-sanitárias, de transporte, de estocagem e de comercialização" (apud ALVES et al., 2002).

A qualidade do pescado também está diretamente relacionada com o local de produção e a comercialização, pois quanto menor for o período entre a produção e o consumo melhor será a sua qualidade, associando assim alta qualidade e preço relativamente baixo. Nas áreas mais distantes da produção, ao serem transportados os pescados perdem em qualidade (tempo) e ganham no preço (frete), tornando-se menos competitivos (SONODA, 2006).

A deterioração de pescados decorre da utilização de substâncias nitrogenadas não protéicas, da decomposição de proteínas e da hidrólise de lipídeos pelos microorganismos, assim como de outras alterações que acarretarão a formação de odores desagradáveis, característicos do pescado deteriorado (LEITÃO; SILVEIRA, 1993).

Bressan e Olalquiaga, citado por Alves et al. (2002), afirma que a rápida deterioração se deve: à reduzida acidez da carne do pescado no armazenamento a fresco, constituindo-se em meio favorável à atuação de bactérias; à ação rápida e descontrolada de suas enzimas, provocando o amolecimento da carne do pescado; à rancidez devido à oxidação lipídica; à ação de sucos 
digestivos que atravessam a parede intestinal, atuando sobre os tecidos musculares e permitindo a invasão de microorganismos que se manifestam sobre as características sensoriais.

O prazo de vida comercial dos peixes é determinado pela quantidade e o tipo de bactérias presentes, bem como pela temperatura empregada no armazenamento dos mesmos (NICKELSON, McCARTHY e FINNE, 2001). LISTON (1980) afirma que a quantidade de bactérias encontradas no pescado em processo de deterioração é alta. Porém, apenas uma parte pode ser denominada de bactérias especificamente deteriorantes. 


\section{CONCLUSÃO}

Este trabalho demonstrou, através da revisão bibliográfica, o crescimento da produção de pescado no âmbito internacional e brasileiro. No levantamento de dados junto ao SIPAG-MAPA, foram detectados como maiores fornecedores de pescado em 2006 ao DF os estados do Pará e Santa Catarina, e ainda identificação da predominância de pescado oriundo de água doce de aproximadamente $42 \%$ do total, sendo a espécie Piramutaba a mais comercializada.

Algumas variedades de pescado comercializadas no Distrito Federal não foram identificadas em função do modelo de controle dos dados aplicado nos entrepostos, dificultando a análise de informações sobre o mercado, variedades e quantidades sobre a demanda da distribuição.

Podemos ressaltar a necessidade e a importância de uma melhor sistematização no registro e coleta de dados sobre a produção, distribuição e comercialização de pescados no Distrito Federal, bem como a realização de novos estudos neste campo, em função do grande crescimento e valorização para o mercado brasileiro. 


\section{REFERÊNCIAS BIBLIOGRÁFICAS}

ABDALlAH, P. R. - Atividade pesqueira no Brasil política e evolução. São Paulo, 1998. 118p. Tese (Doutorado) - Universidade de São Paulo.

ALVES, C. L. et al. Comercialização de pescado no distrito Federal: Avaliação das Condições. Revista Higiene Alimentar, São Paulo, v. 16, nº 102/103, p. 41 - 49, novembro/dezembro, 2002.

ANDRADE, P. F. - Avaliação do prazo de vida comercial do atum (Thunnus atlanticus) armazenado sob refrigeração. Niterói (RJ), 2006. 96p. Tese (Mestrado) - Universidade Federal Fluminense.

BORGES, A. - Qualidade da corvina (Micropogonias furnieri) eviscerada e inteira em diferentes períodos de estocagem à temperatura de $\mathbf{0}^{\circ} \mathbf{C}$. Niterói (RJ), 2005. 81p. Tese (Mestrado) - Universidade Federal Fluminense.

BRASIL, Ministério da Agricultura. Departamento de Produtos de Origem Animal. Decreto $\mathrm{n}^{\mathbf{o}}$ 30691 de 29 de junho de 1952. Aprova Regulamento da Inspeção Industrial e Sanitária de Produtos de Origem Animal. Rio de Janeiro - RJ, 1952.

BRASIL, Ministério da Agricultura. Portaria no 185 de 13 de maio de 1997. Aprova Regulamento Técnico de Identidade e Qualidade de Peixe Fresco (Inteiro e Eviscerado). Brasília - DF, 1997.

BRASIL, Ministério do Meio Ambiente dos Recursos Hídricos e da Amazônia Legal. IBAMA Centro de Pesquisa e Gestão de Recursos Pesqueiros do Litoral Nordeste (CEPENE). Boletim de Estatística da Pesca 2002 - Grandes Regiões e Unidades das Federações. Tamandaré - PE. Brasília - DF, 2002.

BRASIL, Ministério do Meio Ambiente dos Recursos Hídricos e da Amazônia Legal. IBAMA Centro de Pesquisa e Gestão dos Recursos Pesqueiros Lagunares e Estuarinos (CEPERG). Boletim de Estatística da Pesca 2001 - Grandes Regiões e Unidades das Federações. Brasília - DF, 2003.

BRASÍLIA - Distrito Federal. Secretaria de Saúde. Departamento de Saúde Pública Pública. Elabora Manual de Normas Técnicas e Treinamento em Vigilância Epidemiológica. Brasília DF, 1995.

FILHO, J. D. S. - Diretor de Desenvolvimento da Aqüicultura, da Secretaria Especial de Aqüicultura e Pesca, s.d.

FIPERJ - Tabela demonstrativa da posição do Brasil em relação a outros países. Fishstat Plus, FAO 2001, Disponível em: www.fiperj.rj.gov.br. Acesso em: 05 abril, 20007.

FISHTEC, Acervo técnico da Fishtec Consultores Associados, s.d.

FOOD AND AGRICULTURE ORGANIZATION - FAO. The State of World Fisheries and Aquaculture. Rome, 2000. 
FOOD AND AGRICULTURE ORGANIZATION - FAO. Fishery Country Profile. The Federarative Republic of Brazil. Rome, 2001.

FRANCO, B. D. G. M. de; LANDGRAF M. Microbiologia dos Alimentos. São Paulo: Atheneu, 2003.

FRASSER, O. P., SUMAR, S. Compositional Changes and spoilage in fish (part II) microbiological induced deterioration. Nutrition and Food Science, n.6, p. 325-329, 1998.

GIOVA, A. T. APPCC na qualidade e segurança microbiológica dos alimentos. São Paulo: Varella, 1997.

LEITÃO, M. F. de F.; SILVEIRA, N. F. A. Influência da temperatura ambiental na natureza e potencial deteriorador da microbiologia bacteriana de peixes em ambientes lacustres tropicais. Coletânea do ITAL. Campinas, São Paulo: v. 23, nº 1, p. 85 - 97, janeiro/junho, 1993.

LISTON, J. Microbiology in fishery science. CONNEL, J. J. Advances in fishery science and technology. Farnham, England. 1980, p. 138 - 157.

MAUSSE, E. C. J. Shelf life of red fish stored in ice and modified atmosphere (MA) and some aspects on the development of a Quality Index Method (QIM) scheme for red fish stored in MA. Fisheries Training Programme. The United Nations University. Final Project 2000. Beira, Mozambique.

NICKELSON, R.; McCARTHY, S.; FINNE, G. Fish, crustaceans and precooked seafoods. DOWNES, F. P.; ITO, K. Compendium of methods for microbiological examination of foods. 4 ed. Washington. Apha, 2001. 676 p. Cap. 48 p. $497-505$.

OGAWA, M. In: OGAWA, M.; Maia, E. L. Manual de pesca: ciência e tecnologia do pescado. São Paulo: Varela, 1999, p. 4.

OLIVEIRA, J. D. et al. Hábitos e consumo de alimentos. In: . A desnutrição dos pobres e dos ricos: dados sobre alimentação no Brasil. São Paulo: Sarvier, 1996, p. 15 - 30.

SOARES, C. M. Características microbiológicas e físico-químicas do Salmão (Salmo salar) utilizado em sashimis. Revista Higiene Alimentar, São Paulo, v. 19, nº 135, p. 59 - 63, setembro, 2005.

SOARES, V. F. M.; VALE, S. R.; JUNQUEIRA, R. G.; GLÓRIA, M. B. A. Teores de histamina e qualidade físico-química e sensorial de filé de peixe congelado. Ciência e Tecnologia de Alimentos, v.18, n.4, p. 462-470, 1998.

SONODA, D. Y., Demanda por pescado no Brasil entre 2002 e 2003. Piracicaba (SP), 2006. 103 p. Tese (Doutorado) - Universidade de São Paulo.

VALENTI, W. C. Introdução. In: Valenti, W. C. et. Al (Eds.) - Aqüicultura no Brasil: bases para um desenvolvimento sustentável, Brasília: CNPq, p. 25-32, 2000. 